\title{
Damage detection in a reinforced concrete bridge applying wavelet transform in experimental and numerical data
}

\author{
Ramon S. Y. R. C. Silva, Erwin U. L. Palechor, Luciano M. Bezerra \\ Department of Civil Engineering, University of Brasilia Campus Dary Ribeiro SG-12 Brasilia, Distrito Federal, Brazil \\ ramon@unb.br,erwinlopespalechor@botmail.com,lmbz@unb.br
}

Marcus V. G. de Morais

Department of Mechanical Engineering, University of Brasilia, Campus Darcy Ribeiro, Brasilia, Distrito Federal, Brazil mvmorais@unb.br

\section{Welington V. da Silva}

Department of Civil Engineering, University of Brasilia Campus Darcy Ribeiro SG-12 Brasilia, Distrito Federal, Brazil welington.vital@gmail.com

\begin{abstract}
In recent years there has been constant concern in the scientific community to identify techniques for damage detection in structures. Such apprehension has contributed to the progressive development of Structural Health Monitoring. This paper proposes a methodology using Continuous Wavelet Transform associated with interpolation and regularization techniques applied to the experimental and numerical mode shapes of the Dogna Bridge using only the damaged bridge responses. Dogna Bridge is a four-span, single-lane concrete bridge, $64 \mathrm{~m}$ long and $4 \mathrm{~m}$ wide. The results of the analyses are presented and discussed in this paper.
\end{abstract}

KEYwORDs. Wavelet Transform; Dogna Bridge; Structural Health Monitoring.

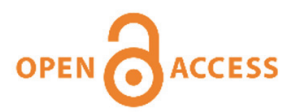

Citation: Silva, R. Y. R. C., Palechor, E. U. L., Bezerra, L, de Morais, M. V. G., da Silva, W. V., N., Damage detection in a reinforced concrete bridge applying wavelet transform in experimental and numerical data, Frattura ed Integrità Strutturale, 48 (2019) 693-705.

Received: 15.06.2018

Accepted: 04.03.2019

Published: 01.04.2019

Copyright: (C) 2019 This is an open access article under the terms of the CC-BY 4.0, which permits unrestricted use, distribution, and reproduction in any medium, provided the original author and source are credited.

\section{INTRODUCTION}

I $\mathrm{n}$ recent years researchers have dedicated considerable attention to the structural safety and reliability of bridges. A substantial number of bridge failures has occurred around the world resulting in economic loss and social consequences. Thus, there is real potential for the application of Structural Health Monitoring (SHM) of bridges to detect and quantify damage. SHM can be used to verify the need for repairs, maintenance, replacement, or even demolition of these structures, thereby protecting the lives of potential users. 
The classical methods of damage detection are based on structural vibrations. Such methods rely on the fact that dynamic characteristics, such as natural frequencies, mode shapes and damping are influenced by the stiffness of the structure [1] (see, for example, detailed studies on damage detection methods based on structural vibrations [2, 3]). The most serious limitation of those methods is the need for a structural response of the healthy structure.

Methods which can detect damage with information obtained from the damage condition of the bridge alone are more appropriate for bridges since their condition before damage is rarely known [4].

It is worth mentioning that another great advantage of wavelet-based methods is that they can be applied both in dynamic responses (mode shapes and frequencies) and in static responses (displacements) [5]. The direct application of Wavelet Transform (WT) to evaluate the structural integrity of bridges has been used by many researchers, see for example [4, 6, 7, $8,9]$. Another approach is the use of damage index, as proposed by [10]. This index is obtained from the ratio between the damaged and the intact acceleration responses.

So far, few tests on damaged bridges have been carried out and made available to researchers working on computational methods to detect damage in structures. Further tests are necessary to provide more data concerning structural bridge variety, different bridge materials, sizes, traffic, environmental conditions and the type of damage. More data on real tests of bridges will contribute to the improvement of the numerical procedures to effectively detect damages in structures.

In this context, no conclusive and efficient method for the effective detection of damages exists. The accuracy of these methods changes with boundary conditions, bridge geometry, material type and the quality of available information. This paper proposes a new methodology to contribute to the SHM methods, using interpolation and regularization techniques to increase the number of reference points and reduce oscillations of the signal data. The proposed methodology is based on real test data and numerical data.

\section{WAVELET TRANSFORM}

I $\mathrm{n}$ the last decade, the wavelet theory has been widely used in various fields of engineering; it has been applied in solving static and dynamic, linear and nonlinear problems of damage detection in structures.

Damage is typically a local phenomenon which may not be apparent in the global vibration response data of the structure. Wavelet Transform (WT) is a signal processing tool that has the ability to identify even small changes in the global response of a signal [11].

\section{Continuous wavelet transform}

In this paper, the wavelet transform is applied to a given signal to provide enhanced frequency-time information of the signal and use that information to detect damage [12]. Generally speaking, the usual time variable employed in classical wavelet theory can be changed to any other variable in which the signal is a function of position. In this research, the wavelet transform will be applied to a set of displacements $\mathrm{u}(\mathrm{x})$ varying along a pre-defined $\mathrm{x}$-axis of a structural member. A wavelet has an average value of zero, so that the following Eq. [1] can be written:

$$
\int_{-\infty}^{\infty} \Psi(X) D X=0
$$

In Eq. (1), the mother wavelet $\Psi(x)$, defined later in this paper, can be used to calculate the analyzed wavelet coefficient $\Psi_{\mathrm{a}, \mathrm{b}}\left(\mathrm{x}_{0}\right)$ defined in the following Eq. (2). Note that the coefficient $\Psi_{\mathrm{a}, \mathrm{b}}\left(\mathrm{x}_{0}\right)$ is defined using 'b', a translation parameter, and 'a' a dilation parameter ${ }^{7}$, as follows:

$$
\Psi_{a, b}\left(x_{0}\right)=\frac{1}{\sqrt{a}} \Psi\left(\frac{x_{0}-b}{a}\right)
$$

Scaling, as a mathematical operation, either dilates or compresses a signal. Larger scales correspond to dilated (or stretched out) signals and smaller scales correspond to compressed signals. Thus in the graphical representation of $\Psi_{\mathrm{a}, \mathrm{b}}\left(\mathrm{x}_{0}\right)$, a little spike corresponds to a high frequency component in the signal and a large spike corresponds to a low frequency component. 
Taking into account $\Psi_{a, b}\left(x_{0}\right)$, the mathematical definition of a Continuous Wavelet Transform (CWT) applied to the displacement signal $\mathrm{u}(\mathrm{x})$ generates a coefficient $C_{a, b}$ that can be expressed in Eq. (3). Note that the CWT coefficient, $C_{a, b}$ , can be interpreted as the sum of all $\mathrm{u}(\mathrm{x})$ along a $\mathrm{x}$-axis, multiplying $\mathrm{u}(\mathrm{x})$ by $\Psi_{a, b}\left(x_{0}\right)$ shifted and scaled. Therefore, the CWT coefficient, $C_{a, b}$, can be defined as:

$$
C_{a, b}=C_{a, b}\left(x_{o}\right)=\int_{-\infty}^{\infty} u(x) \Psi_{a, b}\left(x_{o}\right) d x
$$

These wavelet coefficients are very sensitive to discontinuities and singularities present in the analyzed signal. Considering this property, it was found that damage due to a sudden loss of stiffness can be detected through mode shapes with wavelet coefficients that achieve large amplitudes like a spike or an impulse at the damage location. This spike of the CWT coefficient is due to damage and is clearer in the finest scales of the CWT. This procedure is the basis of CWT damage detection [4].

\section{Proposed Methodology}

7 he proposed methodology is based on the use of three well-known techniques; Interpolation, Regularization and Continuous Wavelet Transform. Interpolation functions expand the information data available at a few points to many other points, thereby helping damage detection. In this paper researchers will note that, despite the differences between real data and simulated data; the proposed methodology, leads, in the cases analyzed, to the correct detection of the damage. Such methodology can be applied to mode shapes of bridge structures using experimental data or computationally simulated numerical data too. Another advantage is that it is not necessary to have the reference mode shapes of the undamaged or original structure. The methodology is divided into six main steps is shown in Fig. 1.

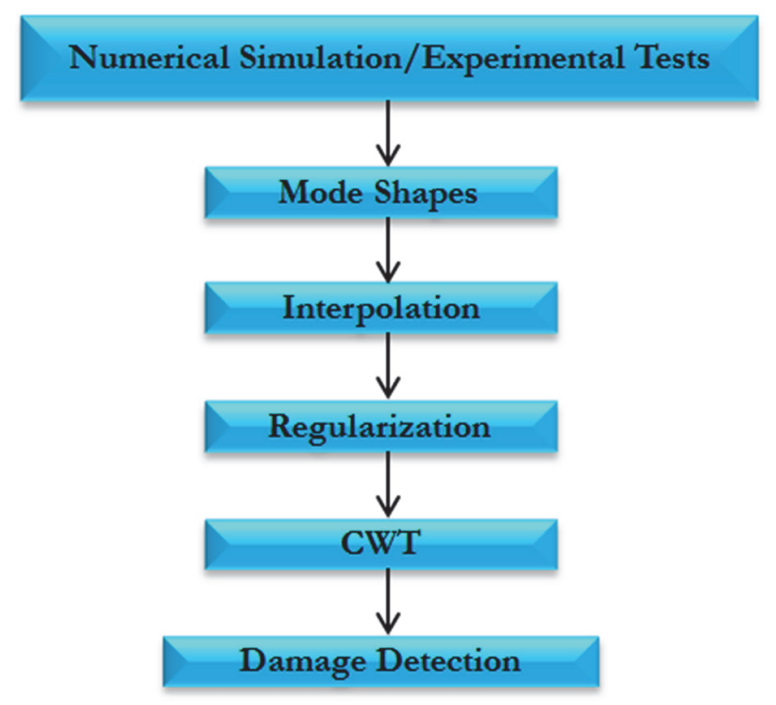

Figure 1: Flowchart of the proposed methodology.

In this paper, either experimental tests or numerical simulation are used to illustrate the proposed methodology. The main steps represented in Fig. 1 are described as follows:

- STEP-1: Experimental Tests or Numerical Simulation: The first step consists of carrying out real experimental tests or numerical simulation of the damaged structure.

- STEP-2: Mode Shapes: From the previous step, mode shapes of the damaged structure are found. The mode shapes are the basic data that will be used in the next steps. 
- STEP-3: Interpolation: Generally, in experimental tests only a small amount of measured data is available and this limitation makes the damage detection process difficult. To overcome that limitation, it is necessary to apply an interpolation technique to obtain more results or more data. The technique chosen here was the cubic spline. That choice showed better results when compared to other interpolation techniques such as Bézier, Polynomial and P-chip as explained in [13]. With such interpolation the mode shape information (data) is extended to other locations not previously measured.

- STEP-4: Regularization: After the interpolation of the mode shapes, the Tikhonov Regularization technique is applied [14] to reduce the numerical oscillations of the signal (data).

- STEP-5: Continuous Wavelet Transform (CWT): Apply the CWT in the regularized mode shape to compute the wavelet coefficients using the Eq. (3). The mother wavelets chosen were: (a) the Daubechies5 (Db5), and (b) the Coiflet4 (Coif4). Such choices represent the best results when compared to other 52 mother wavelets studied in [13].

- STEP-6: Damage Detection: After the wavelet coefficients have been calculated and plotted, the plots are evaluated. The discontinuities in the plots can be easily seen and they correspond to wavelet coefficients reaching large amplitudes in the damaged region.

The methodology in Fig. 1 is applied in the next sections to a real situation and to a simulated situation. The number of damage sites may be derived from the appropriate interpretation of the discontinuities in the plots of the wavelet coefficients, as in STEP-5 (for more information see [15]).

\section{METHODOLOGY APPLICATION TO A REAL PROBLEM}

$\mathrm{D}$

ogna bridge crosses the River Fella and connects the villages of Crivera and Valdogna in a region located in the North East of Italy. The bridge is a four-span, single-lane structure, made of reinforced concrete, $64 \mathrm{~m}$ long, and $4 \mathrm{~m}$ wide - Fig. 2a. The length of each span is $16 \mathrm{~m}$. The bridge deck in reinforced concrete is an $18 \mathrm{~cm}$-thick slab supported by three longitudinal beams with rectangular cross-sections $35 \mathrm{~cm}$ wide and $120 \mathrm{~cm}$ high (see Fig. 2b). A transversal cut of the bridge deck and the three longitudinal beam sections can be seen in Fig. 2c. Progressive damage is introduced to the bridge beam and will be detailed in the next sections.

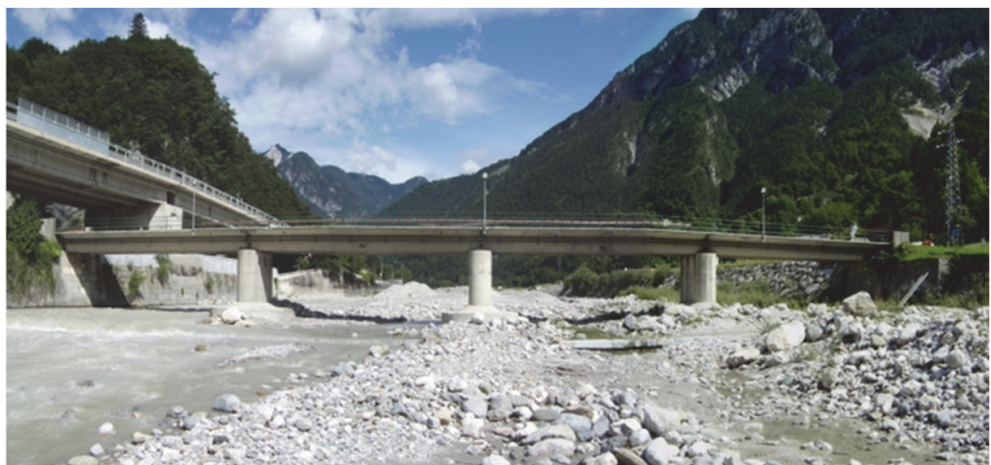

(a)
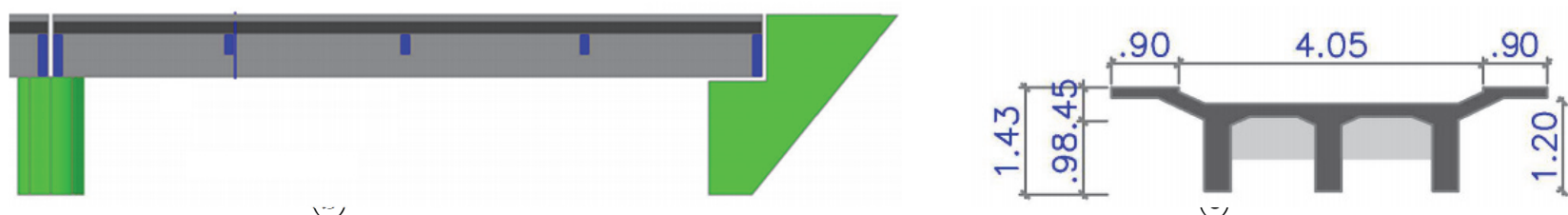

Figure 2: Dogna Bridge: (a) General overview; (b) Longitudinal view; (c) Transversal section.

\section{Dynamic tests of the damaged bridge}

To obtain the dynamic properties of the structure, two different types of tests were carried out. Dynamic tests took into account progressive damage introduced in one of the bridge beams. The tests correspond to harmonically forced vibration tests and ambient vibration tests. Only the ambient vibration tests were available to be used in this paper. In such tests, ten 
accelerometers were positioned in a vertical direction as illustrated in Fig. 3. All the experimental accelerations of the intact bridge and the damaged bridge cases were provided by the Structural Vibration and Solutions (SVIBS) company which developed the ARTeMIS software [16].
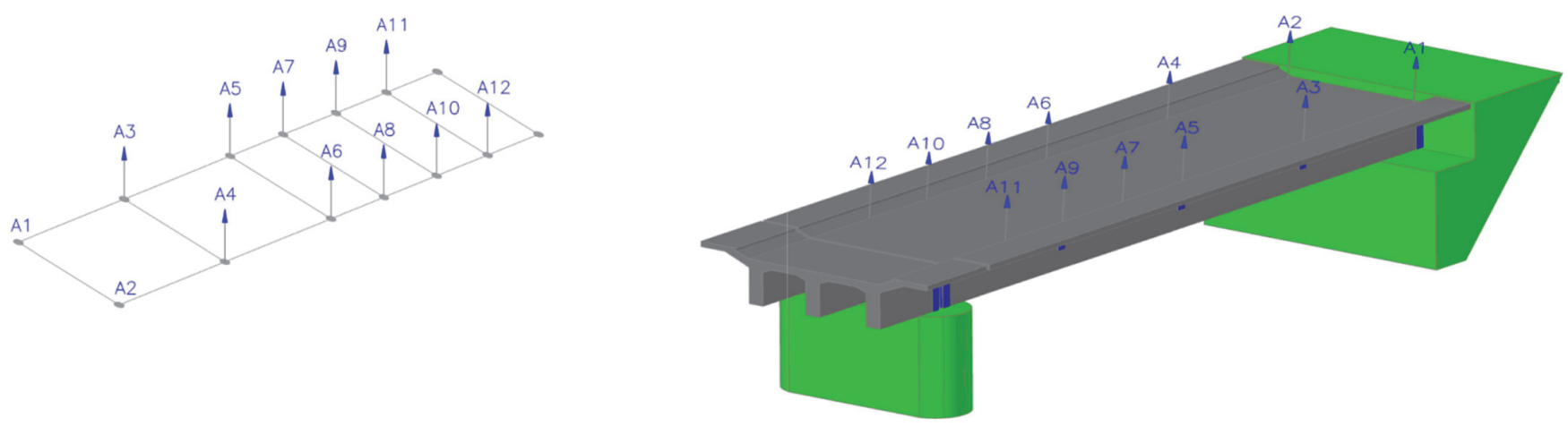

Fig. 3. Instrumentation used in the bridge: (a) Instrumental layout;(b) Longitudinal view.

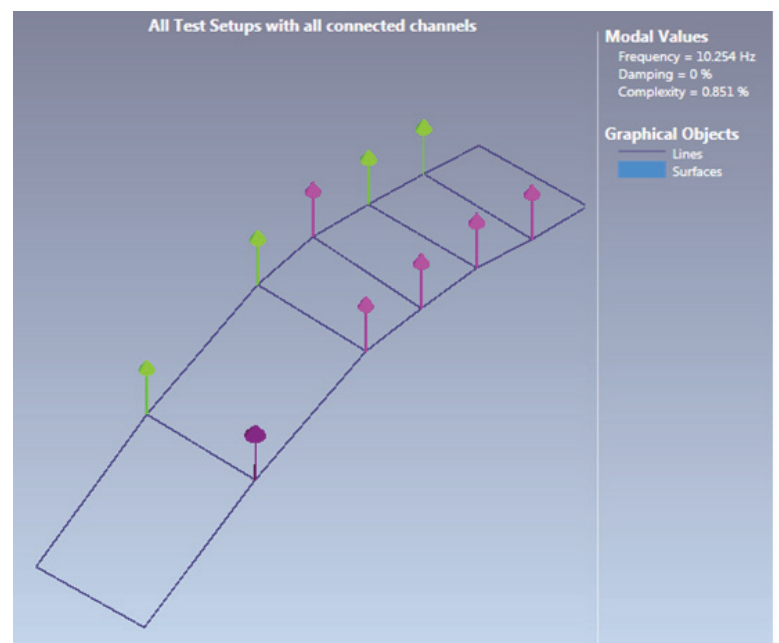

(a)

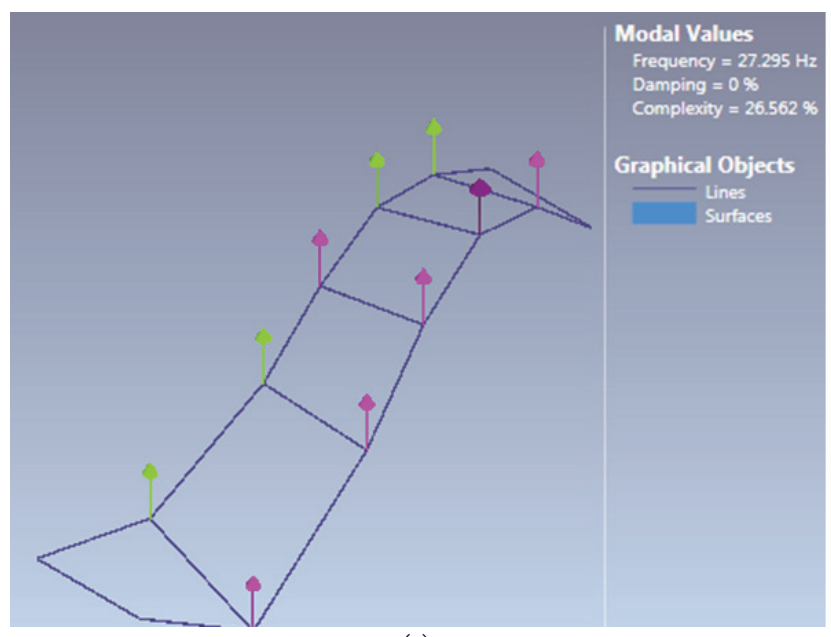

(c)

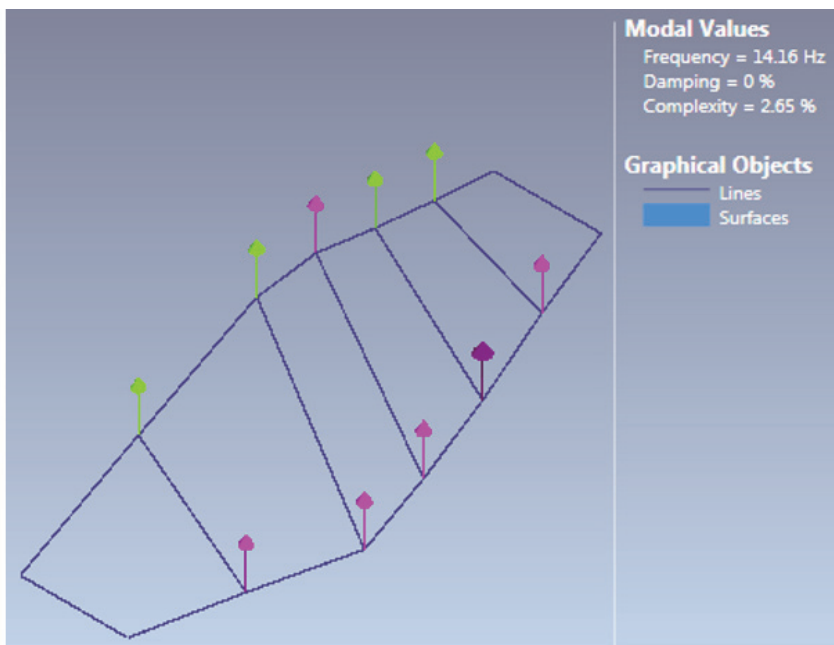

(b)

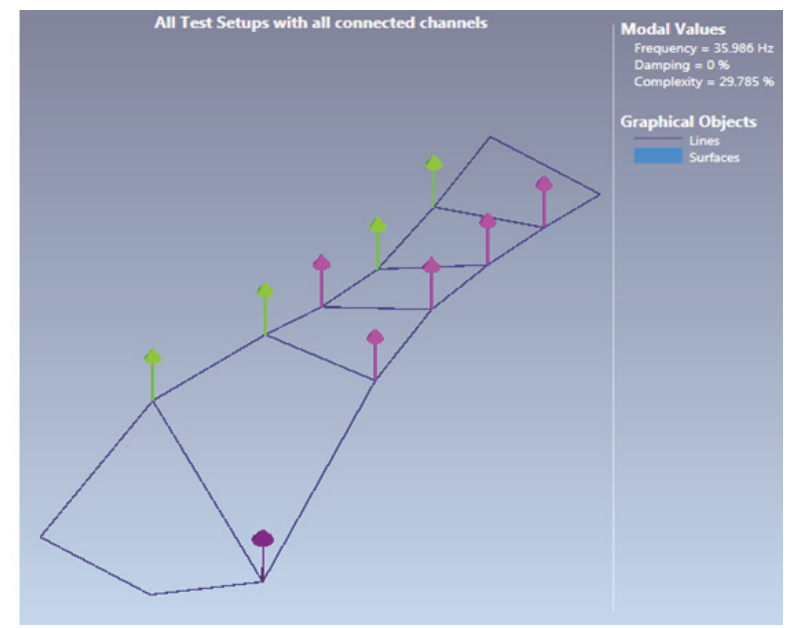

(d)

Figure 4: Experimental natural frequencies and mode shapes: (a) First flexural mode shape; (b) First torsional mode shape; (c) Second torsional mode shape; (d) Third torsional mode shape. 
Before the progressive damage was artificially introduced, a reference Ambient Vibration Test was conducted for 20 minutes in 10 locations of the bridge span. The total number of samples acquired was $475,341\left(\approx 4.75 \times 10^{5}\right.$ samples $)$. The identification of the frequencies and mode shapes was performed using the Frequency Domain Decomposition (FDD) method available in the ARTeMIS software [16]. Fig. 4 illustrates the first four modes of shapes of the undamaged bridge structure. Fig. 5 shows the curves of the average normalized singular values of the spectral density matrices of all experimental setups. Fig. 6 shows the values of the Auto MAC correlation matrix of the experimental mode shapes obtained by the application of the FDD method.

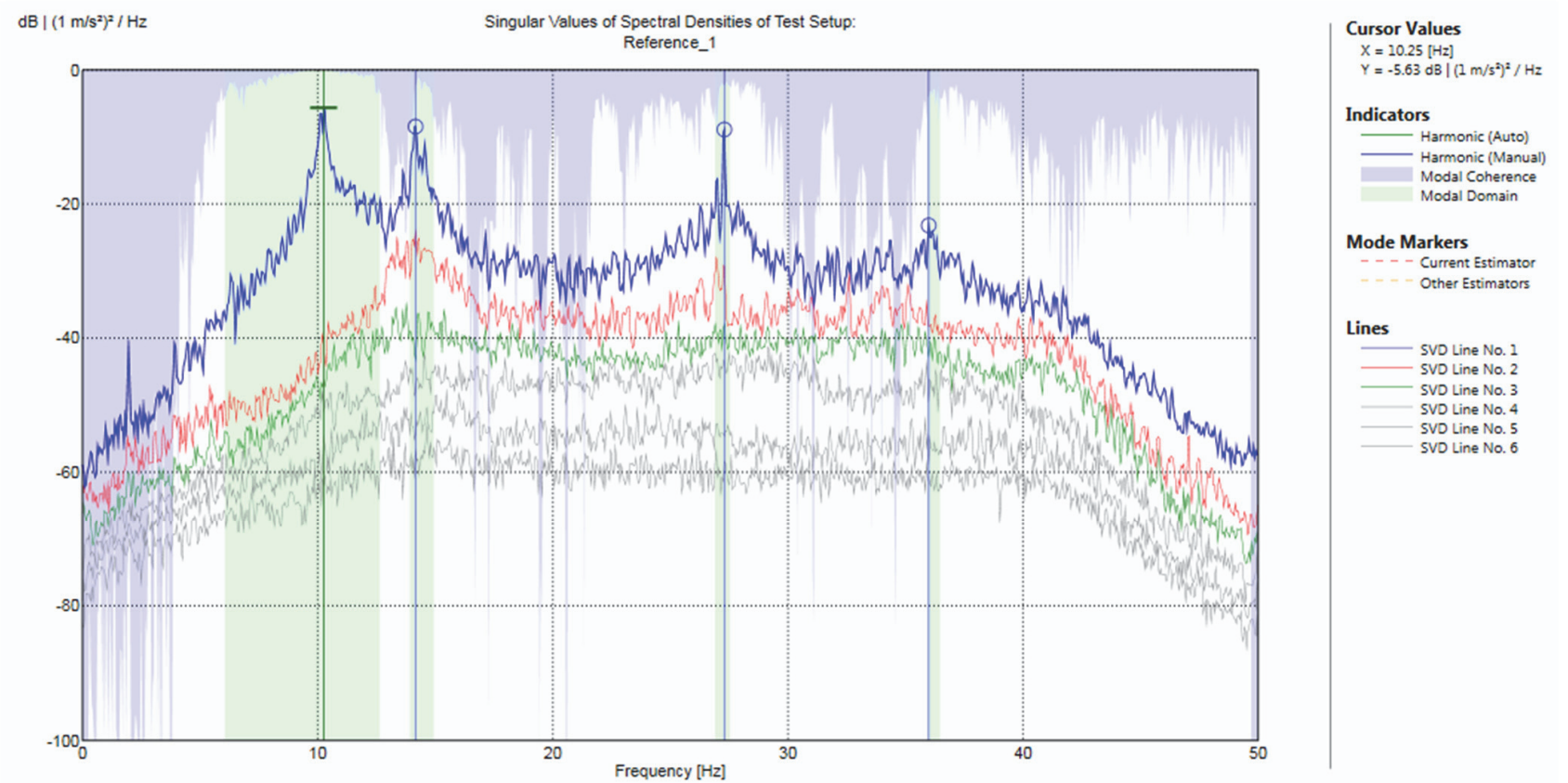

Figure 5: FDD method: average normalized singular values of the spectral density matrices.

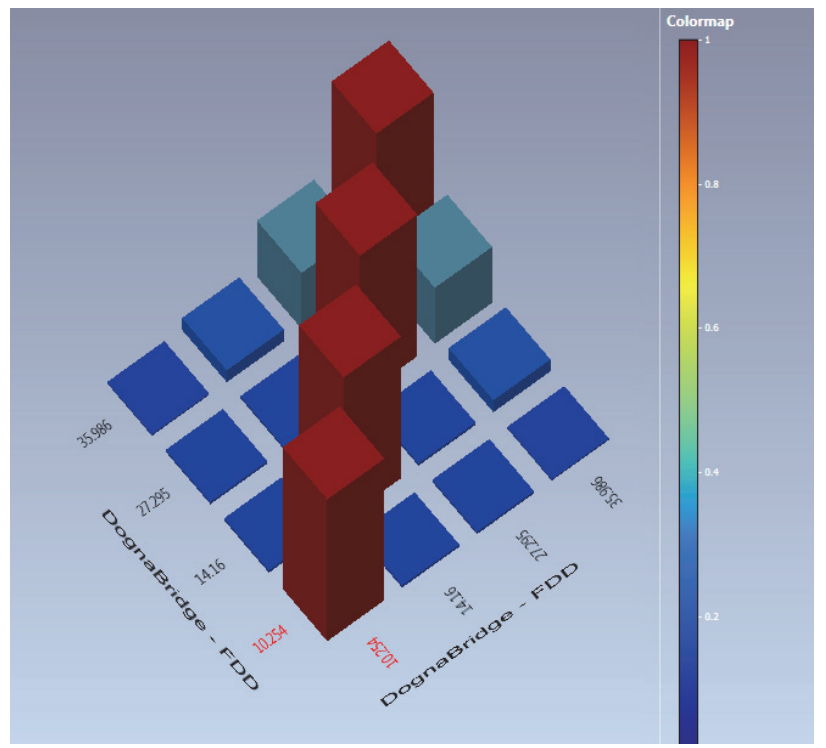

Figure 6: AutoMAC correlation matrix of experimental mode shapes using the FDD method.

\section{Damage cases}

The experimental campaign had seven progressive damage cases. However, this paper presents the results of only one experimental damage case. Moreover, this research also presents numerically simulated damage cases to show the 
effectiveness and applicability of the methodology proposed in Section 3 of this paper. Fig. 7 shows details of two of the damage cases studied in this research.

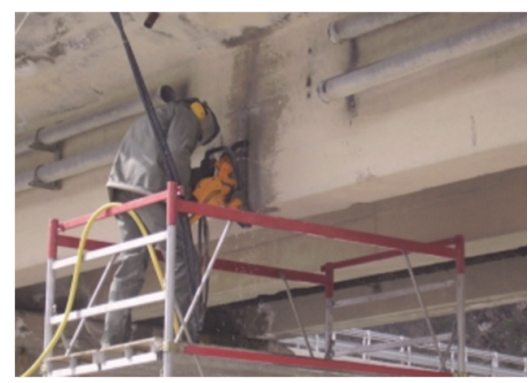

(a)

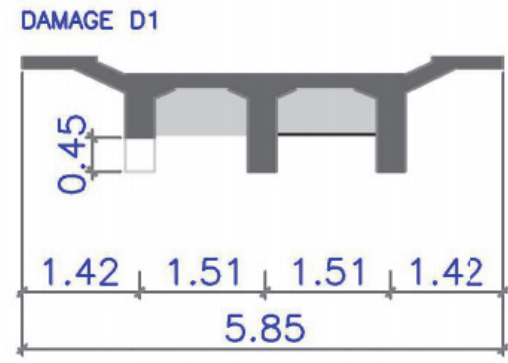

(b)

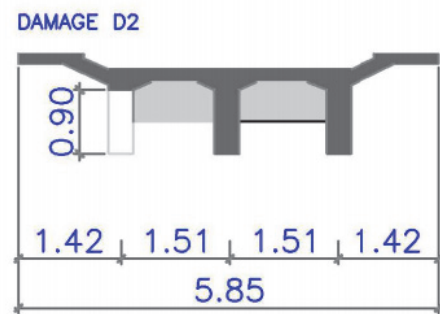

(c)

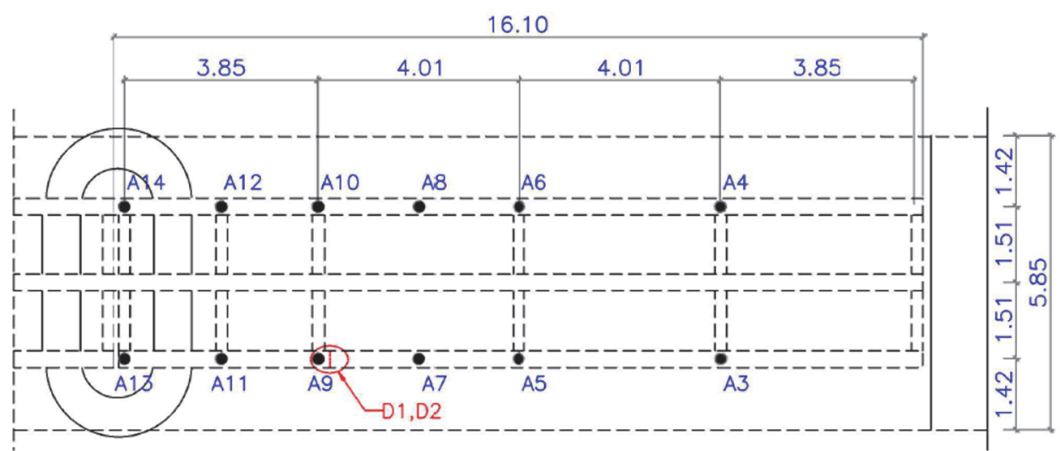

(d)

Figure 7: Damage cases: (a) Damage artificially introduced; (b) Damage D1; (c) Damage D2; (d)Plan view of the damage positions.

Damage D1 consists of a half cut along the height of the external beam. Damage D2 is a complete cut of $1 \mathrm{~cm}$ width along the height of the beam. Damages D1 and D2 represent reductions, in different measure, of the cross section area of the bridge beam corresponding to $8 \%$ and $16 \%$, respectively. Tab. 1 presents the experimental natural frequencies obtained from the ARTeMIS software [16].

\begin{tabular}{ccc}
\hline Mode & Intact & Case D1 \\
$1^{\mathrm{o}}$ & 10.25 & 9.96 \\
$2^{\mathrm{o}}$ & 14.16 & 14.06 \\
$3^{\mathrm{o}}$ & 27.29 & 27.63 \\
$4^{\mathrm{o}}$ & 35.98 & 35.32 \\
\hline
\end{tabular}

Table 1: Experimental natural frequencies $(\mathrm{Hz})$.

The damage detection was done by taking into account only the damaged mode shape in case D1. The data of five points corresponding to the first experimental mode shape of each line of the bridge (Fig. 3) were exported to MATLAB and then Cubic-Spline interpolation was used to increase the number of data from 5 points to 1,000 points. After interpolations, the Tikhonov regularization technique was applied to the interpolated mode shapes. As explained in the flowchart in Fig. 1, the last but one step of the proposed methodology is the application of CWT. The results of CW'T application are presented in Figs. 8 and 9, respectively, for the Daubechies5 (Db5) and the Coiflet4 (Coif4) mother wavelets.

Figs. 8 and 9 show the CWT results of damage case D1 adopting, respectively, the Daubechies and Coiflet wavelets. Notice that in this case just a single crack is present. In Fig. 8 and 9, the left and right plots, respectively, represent the CWT analysis in $3 \mathrm{D}$ and $2 \mathrm{D}$.

In these figures it can be observed that the wavelet coefficients in the damaged region achieved very large amplitudes due to the singularities in the sign (mode shape data) caused by the presence of the damage D1. 


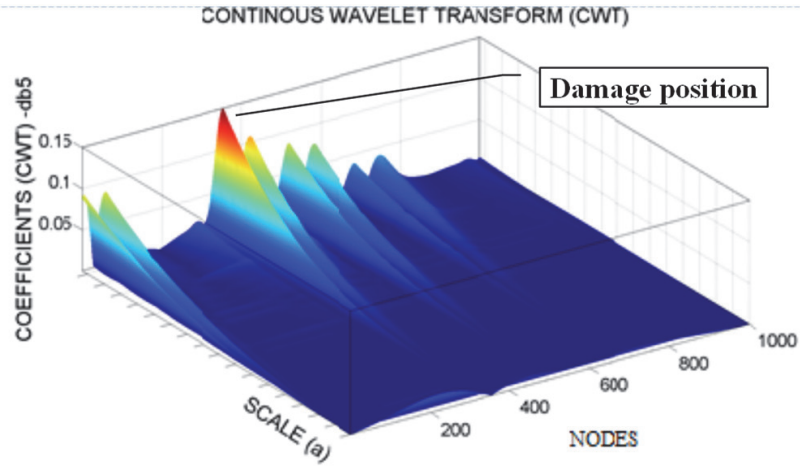

(a)

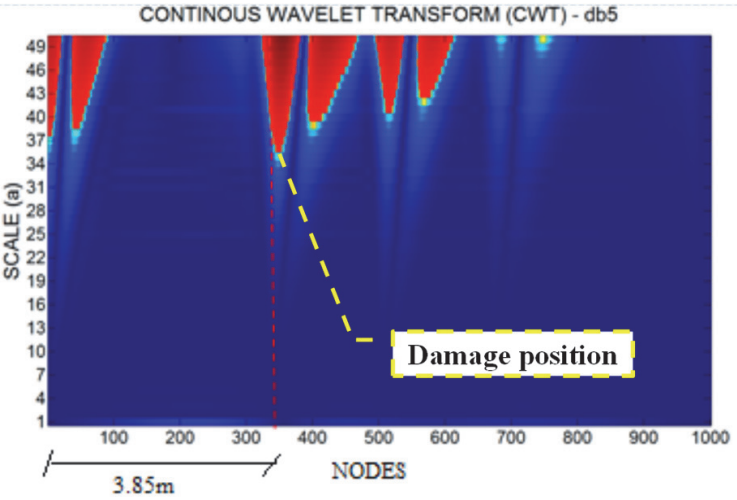

(b)

Figure 8: CWT using Db5-Case D1: (a) 3D view; (b) 2D view.

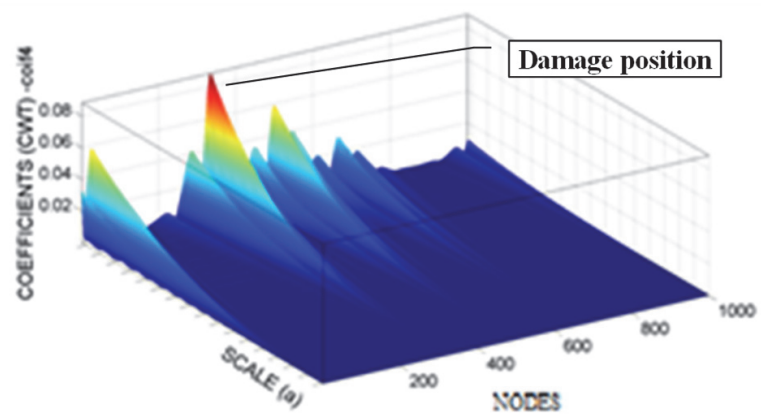

(a)

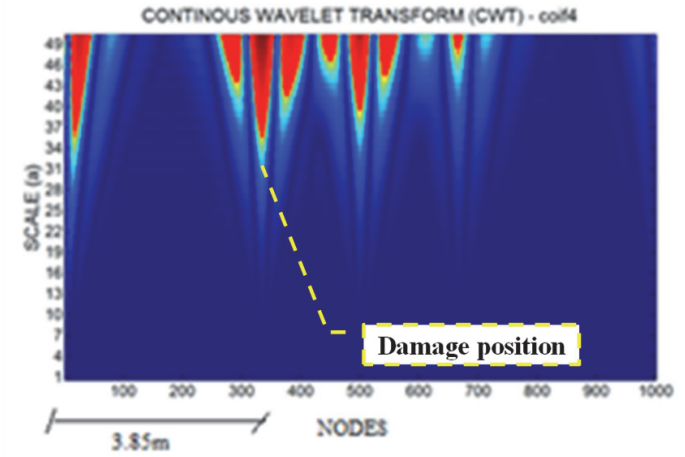

(b)

Figure 9: CWT using Coif4-Case D1: (a) 3D view; (b) 2D view.

\section{NUMERICAL MODELING}

I $\mathrm{n}$ order to shown the applicability of the methodology proposed in this paper - seen section 3, a numerical example is presented in this section. The numerical analysis was developed using the ANSYS [17] software in order to reproduce the same conditions for dynamic testing. This time, however, the numerical modeling simulates the introduction of two induced damages, D1 and D2. Both damages are located in one external beam. Natural frequencies and mode shapes are found with the numerical model. The reinforced concrete bridge was simulated using the element SOLID65 (3-D Reinforced Concrete Solid) presented in Fig. 10(a). The element is defined by eight nodes having three degrees of freedom at each node: translations in the nodal $\mathrm{x}, \mathrm{y}$, and $\mathrm{z}$ directions.

The degrees of freedom on the supports were modeled by imposing nodal displacement constraint at the ends of the longitudinal beams.

The mechanical properties assumed in the modal analysis to find the natural frequencies and mode shapes in the two damage scenarios are presented in Tab. 2. In order to simulate the two damage scenarios, some elements from the refined mesh were deleted, as can be seen Fig. 11.

\begin{tabular}{cccc}
\hline Case & $\begin{array}{c}\text { Modulus of elasticity } \\
(\mathrm{GPa})\end{array}$ & Poisson's Ratio & Density $\left(\mathrm{kg} / \mathrm{m}^{3}\right)$ \\
D1 & 32 & 0.2 & 2500 \\
D2 & 32 & 0.2 & 2500 \\
\hline
\end{tabular}

Table 2: Mechanical properties of the reinforced concrete. 


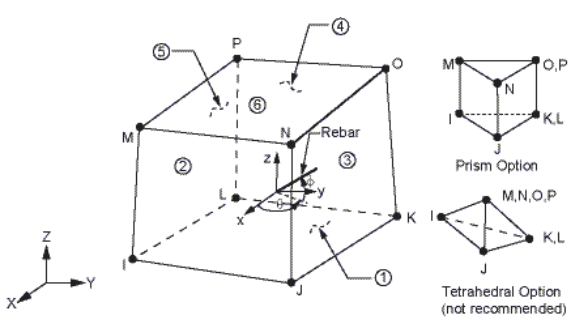

(a)

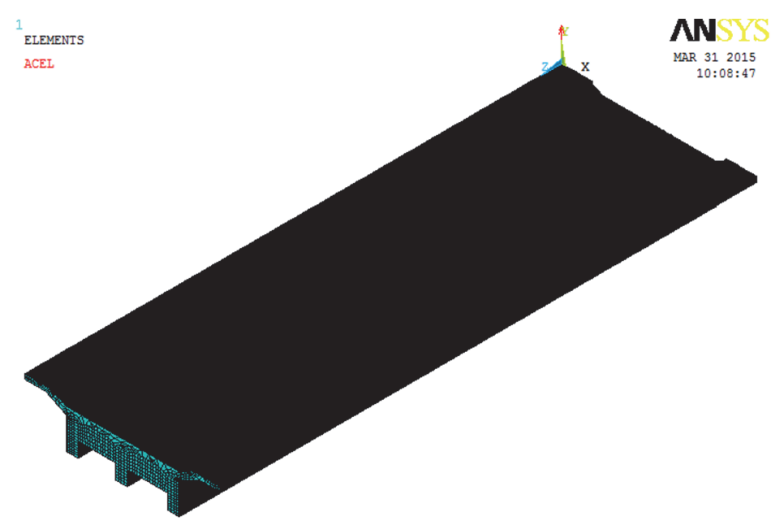

(b)

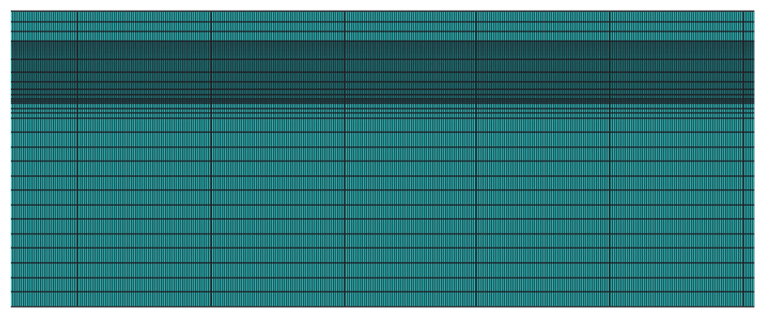

(c)

Figure 10: Numerical model: (a) SOLID65 element; (b) 3D view; (c) Detail of longitudinal view.

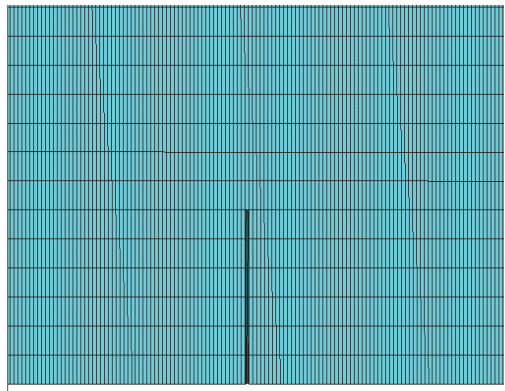

Figure 11: Numerical simulation of the damage D1.

Figs. 12, 13, 14, and 15 present the mode shapes obtained in the modal analysis for the undamaged bridge. Tab. 3 presents the values of numerical natural frequencies of the intact and the damaged bridge.

\begin{tabular}{cccc}
\hline Mode & Intact & Case D1 & Case D2 \\
$1^{\circ}$ & 12.09 & 12.08 & 12.07 \\
$2^{\circ}$ & 13.06 & 13.05 & 13.05 \\
$3^{\circ}$ & 25.72 & 25.72 & 25.69 \\
$4^{\circ}$ & 38.29 & 38.28 & 28.27 \\
\hline
\end{tabular}

Table 3: Numerical Natural frequencies $(\mathrm{Hz})$.

The damage detection using numerical mode shape was done in a similar way as was done in the experimental case presented in Section 4 of this paper. The same five positions, corresponding to accelerometers, as used in the experimental tests were adopted in the numerical modeling. From the numerical data of five points corresponding to the first numerical mode shapes of each line of the bridge, the corresponding mode shape data was exported to MATLAB. Cubic-Spline interpolation was used in MATLAB to increase the number of data (from 5 points to 1,000 points). After interpolations, the Tikhonov 
regularization technique was applied to the interpolated mode shapes. As explained in the flowchart presented in Fig. 1, the last but one step of the proposed methodology is applied determining the CWTs. The results of CWT application are presented in Figs. 15 to 18 for the Daubechies5 (Db5) and the Coiflet4 (Coif4) mother wavelets.

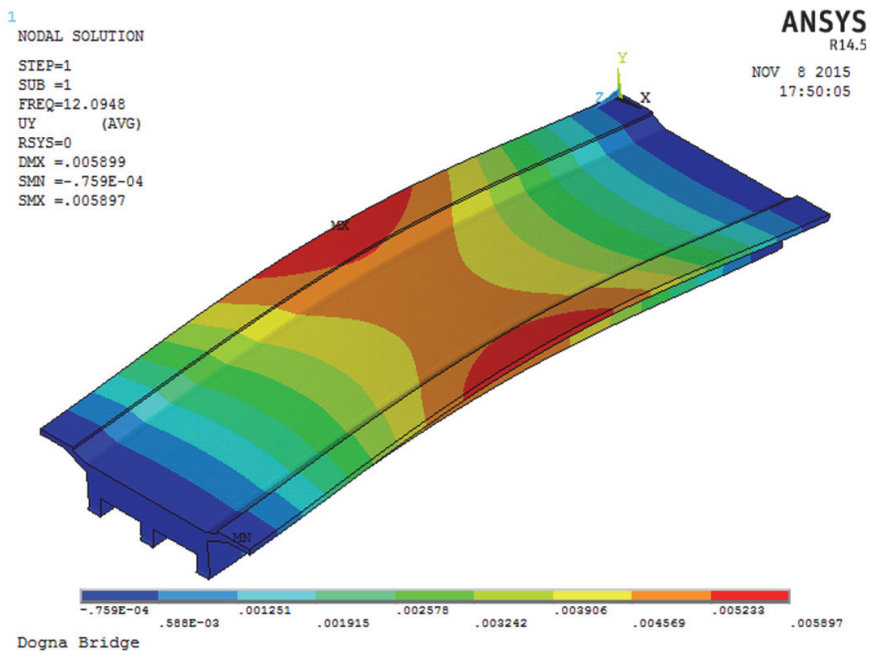

Figure 12: First mode shape- $\mathrm{f1}=12.09 \mathrm{~Hz}$.

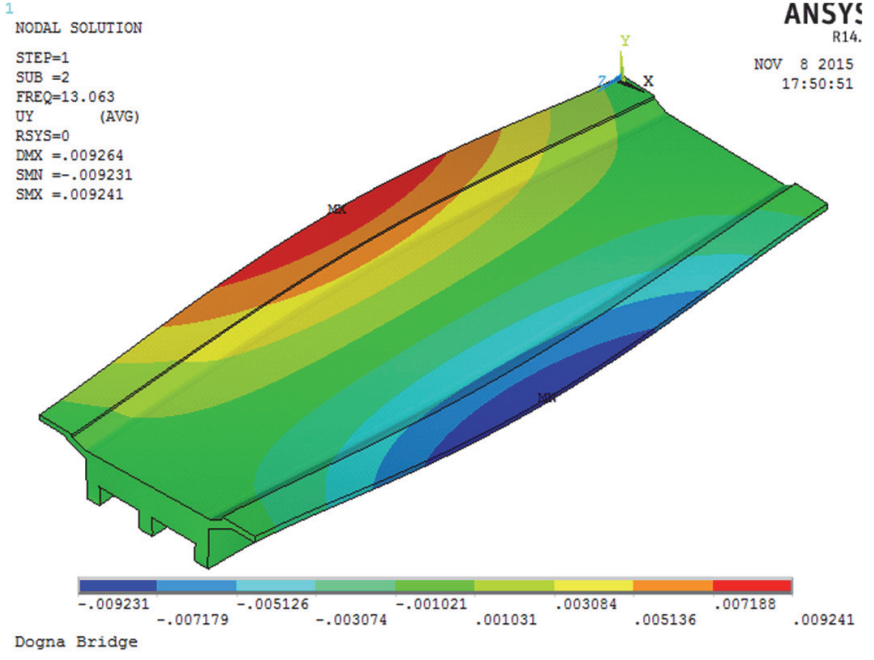

Figure 13: Second mode shape-f2 $=13.06 \mathrm{~Hz}$.

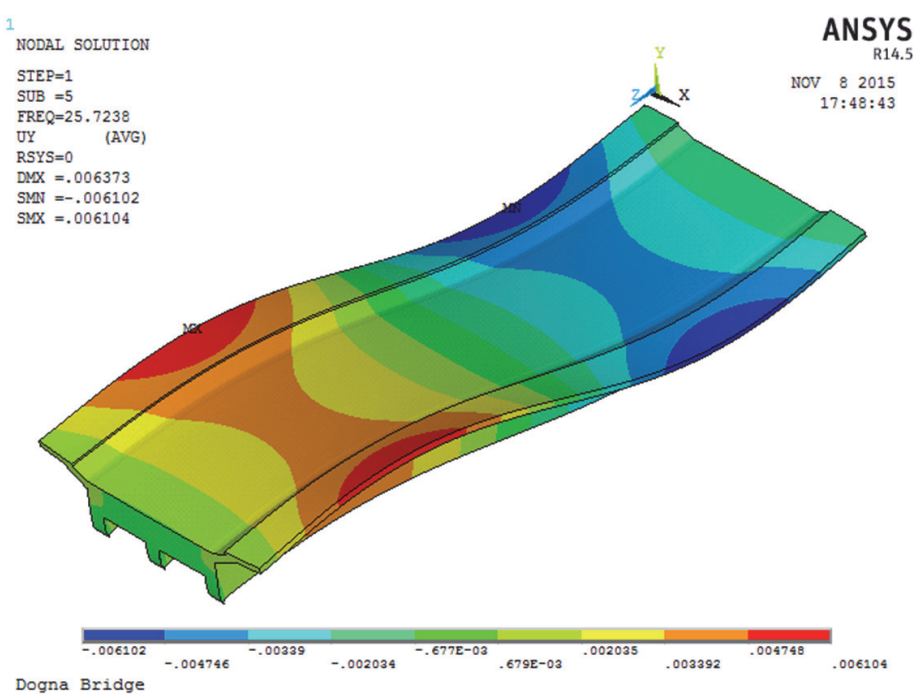

Figure 14: Fourth mode shape-f4=38.29Hz.

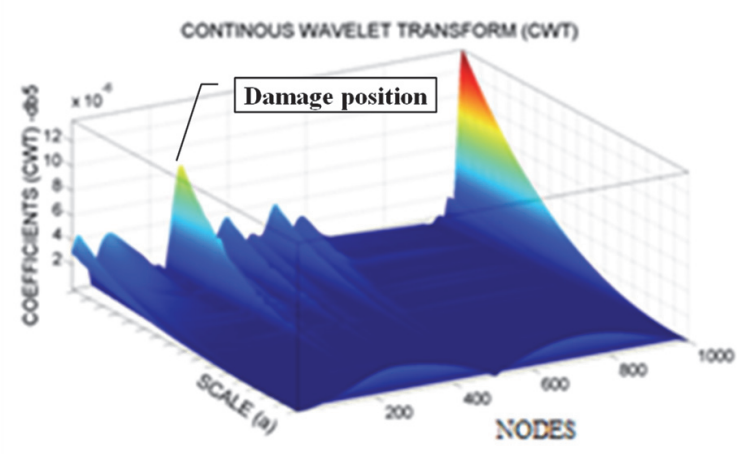

(a)

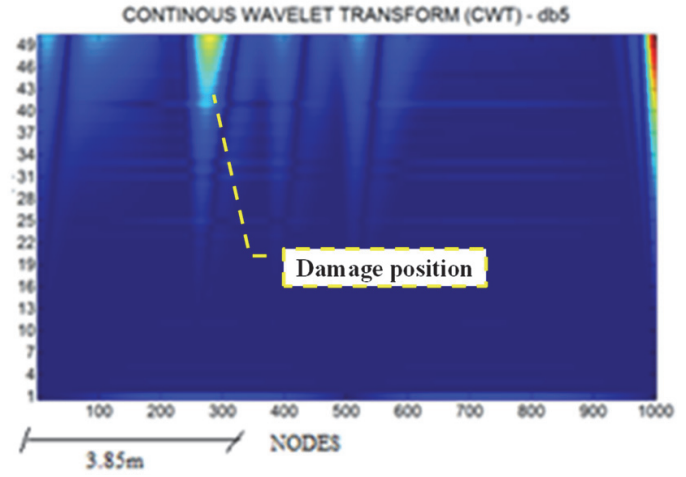

(b)

Figure 15: CWT using Db5-Case D1: (a) 3D view; (b) 2D view. 


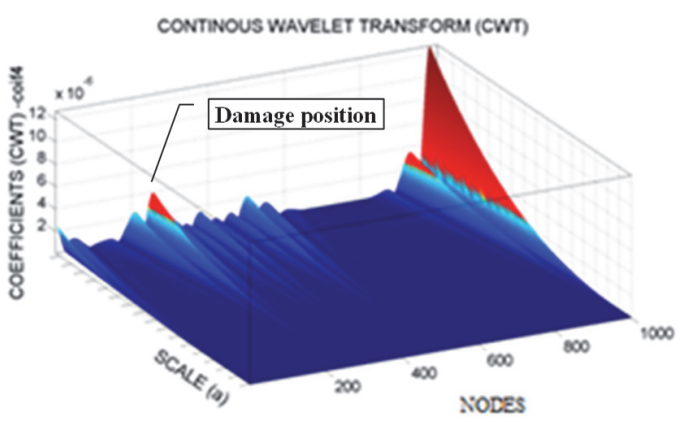

(a)

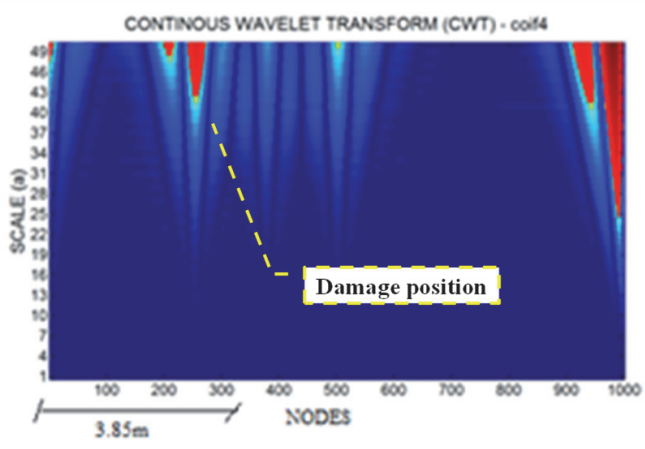

(b)

Figure 16: CWT using Coif4-Case D1: (a) 3D view; (b) 2D view.

As the results suggest in Figs. 15, 16, 17, and 18, the largest amplitude wavelet coefficients peaks are associated with the damage area for cases D1 and D2. Nevertheless, considerable values also occurred at the boundaries of the bridge. This effect has been observed by many authors $[8,18]$.

In Figs. 15 and 16, the left and right plots, respectively, represent the CWT analysis in 3D and 2D. In these figures, it can be observed that the wavelet coefficients in the damaged region achieved very large amplitudes due to the singularities in the sign (mode shape data) caused by the presence of the damage D1.

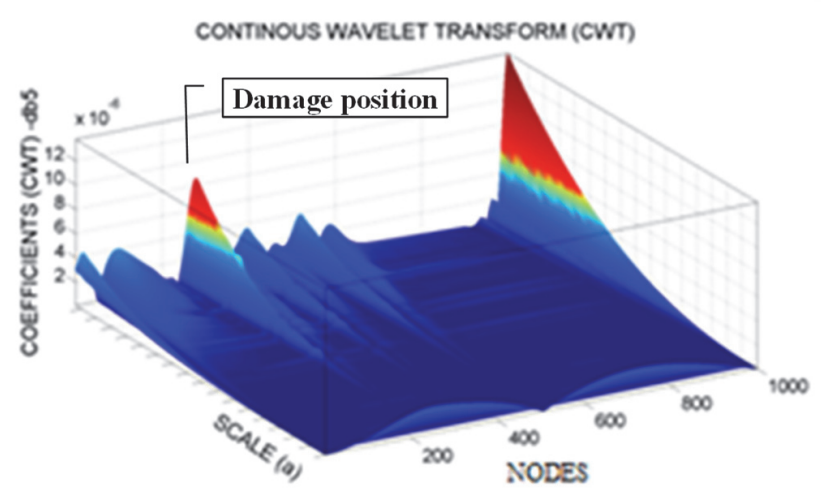

(a)

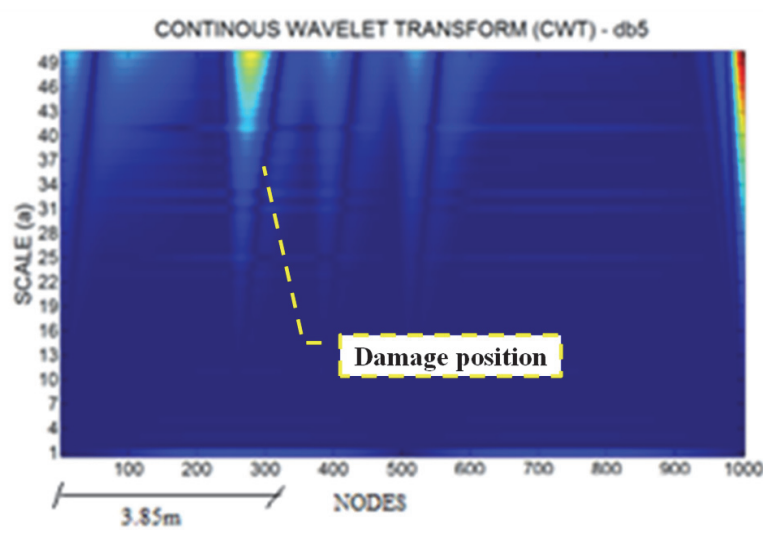

(b)

Figure 17: CWT using Db5-Case D2: (a) 3D view; (b) 2D view.

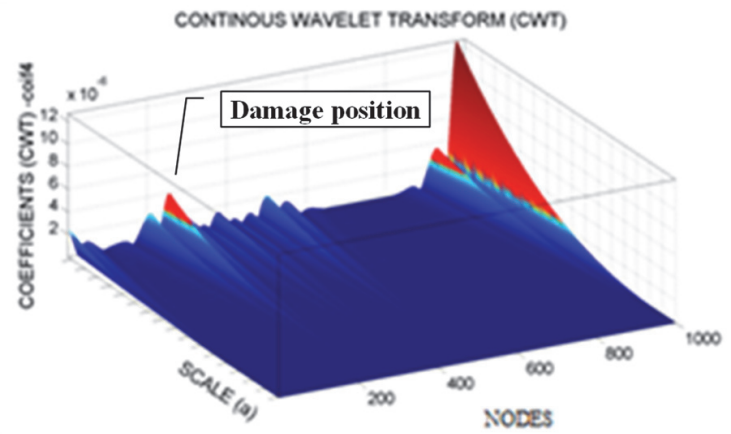

(a)

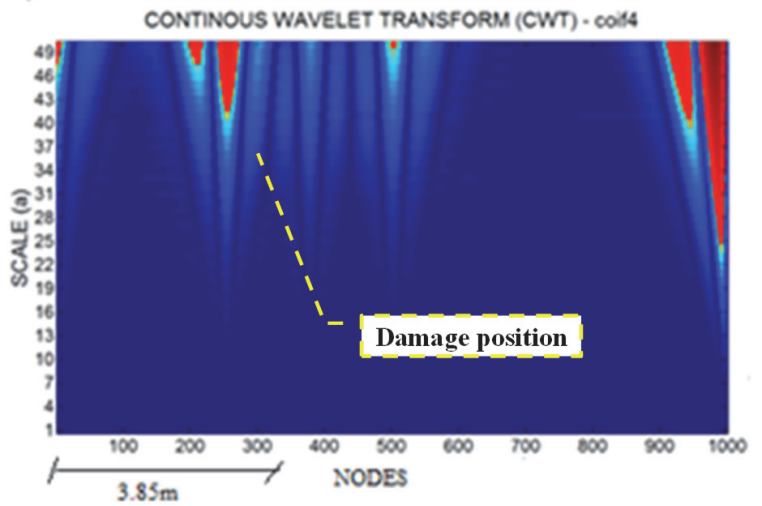

(b)

Figure 18: CWT using Coif4-Case D2: (a) 3D view; (b) 2D view. 


\section{CONCLUSIONS}

$\mathrm{I}$

$\mathrm{n}$ this paper a methodology based on Continuous Wavelet Transform associated with interpolation and regularization techniques for detection of damage in a real bridge using numerical and experimental data are presented. Two wavelets, Daubechies and Coiflet are applied to the mode shapes obtained. Current research of wavelet analyses for damage assessment leads to the following conclusions.

- Damage is successfully localized by the wavelet coefficients that achieved large values in the damaged positions.

- The proposed methodology can be implemented without the need for the dynamic data of an intact structure as a starting point for damage detection.

- The proposed methodology can be applied to detect damage of small dimension.

- The use of a small number of measurement points is a drawback that can be overcome by using interpolation techniques.

- Signal noises at the extremities of the structure are due to discontinuities at those positions. At those points damage identification is difficult.

- The methodology proposed here can help to reduce bridge inspection tasks. From the results obtained at a few points, using the proposed methodology a possible damage area can be pointed out. Therefore, with that indication, a detailed inspection could be done just in the indicated area. No examination extended to a larger area is necessary.

- The proposed methodology in this paper is a reliable approach for damage detection in bridges.

\section{REFERENCES}

[1] Janeliukstis, R., Rucevskis, S., Wesolowski, M., Chate, A. (2017). Experimental structural damage localization in beam structure using spatial continuous wavelet transform and mode shape curvature methods, Measurement 102, pp. 253270.

[2] Friswell, M.I. (2007). Damage identification using inverse methods, Phil. Trans. R. Soc. A. 365, pp. 393-410.

[3] Fan, W., Qiao, P. (2011). Vibration-based damage identification methods: a review and comparative study, Struct. Health Monit. 10, pp. 83-111.

[4] Estrada, E. S. (2008). Damage detection methods in bridges trough vibration monitoring: evaluation and application. Guimarães, Doctoral Thesis, University of Minho, 289p.

[5] Silva, R. S. Y. R C. (2015). Monitoring and numerical and experimental identification of damages in steel and concrete beams and bridges using wavelet transform. Brasília, PhD Thesis, University of Brasília, 240p (in Portuguese).

[6] Weibing, H., Wei, H., Yu, Z. (2010). Wavelet analysis in damage detection for bridge structure. Key Engineering Materials 417, pp. 813-816.

[7] Sun, Z., Chang, C. (2002). Structural damage assessment based on wavelet packet transform. Journal of Structural Engineering 128, pp. 1354-1361.

[8] Alvandi, A., Bastien, J., Gregoire, E., Jolin, M. (2009). Bridge integrity assessment by continuous wavelet transforms. International Journal of Structural Stability and Dynamics 9, pp. 11-43.

[9] Li, Z. H., Au, F. T. K. (2015). Damage detection of bridges using response of vehicle considering road surface roughness. International Journal of Structural Stability and Dynamics 3, pp. 1-23.

[10] Golmohamadi, M., Badri, H., Ebrahimi, A. (2012). Damage diagnosis in bridges using wavelet. International Conference on Technological Advancements in Civil Engineering, Coimbatore, Índia.

[11] Rajendran, P., Sivakumar, M. S. (2015). Rotational-mode-shape-based added mass identification using wavelet transform International. Journal for Computational Methods in Engineering Science and Mechanics 16, pp. 182-187.

[12] Hester, D., González, A. (2011). A wavelet-based damage detection algorithm based on bridge acceleration response to a vehicle. Mechanical Systems and Signal Processing 28, pp. 145-166.

[13] Palechor, E. U. L. (2014). Identification of damages in metallic beams using wavelets and numerical and experimental data. Brasília Master Thesis - University of Brasília, 299p (in Portuguese).

[14] Tikhonov, A. N., Arsenin, V. Y. (1977). Solutions of Ill-posed Problems. John Wiley, New York.

[15] Ovanesova, A. V., Suárez, L. E. (2004). Applications of wavelet transforms to damage detection in frame structures. Journal Engineering Structures 26, pp. 39-49.

[16] ARTeMIS. ARTeMIS Extractor pro. Academic license. User's manual (2009). In:ApS SVS, editor. Aalborg, Denmark. 
[17] ANSYS. Structural analysis guide - release 11.0. In: ANSYS (2007).

[18] Palechor, E. U. L., Silva, R. S .Y. R. C, Bezerra, L. M., Bittencourt, T. N. (2014). Damage detection in beams using experimental data. Key Eng. Materials, 607, pp.21-29. 